\title{
Arthropods as Vectors and Reservoirs of Animal Pathogenic Viruses.
}

\author{
By WilliaM C. REeves
}

School of Public Health, University of California, Berkeley, California.

Arthropods have been serving undoubtedly as vectors and possibly as reservoirs of virus diseases of man and other vertebrates for many centuries. However, recognition of the viral etiology and role of arthropods as vectors for these infections has all ensued in the twentieth century; and the majority of our knowledge has accrued in the past 25 years. These infections have received major attention in this period; and as a result the group is no longer limited to the classical triad of viral agents which cause yellow fever, dengue and sand fly fevers, but instead encompasses nearly 50 distinct viruses. Inevitably additional etiological agents in this group remain to be discovered, as is evidenced by the knowledge that several laboratories have isolated such agents but have not reported them in the literature, and there is a continuing intensive search for additional agents. It must be assumed that virus diseases will soon constitute the largest group of arthropod-borne animal infections, if they do not already exceed the vector borne infections of animals caused by protozoa, bacteria or rickettsiae.

Currently there is the unusual epidemiological circumstance that a number of viral agents are isolated from arthropods previous to recognition of any disease syndrome they might naturally cause in animal hosts. This is a complete reversal of a classical epidemiological evolution in which descriptive analysis of a series of cases led to incrimination and subsequent proof of an arthropod vector and viral etiology. Viral agents are now being isolated in experimental hosts by inoculation of wild arthropod vectors, and subsequently a search is made for evidence of naturally occurring infection or disease in man and other vertebrates throughout the world.

This consideration will be limited to the group of viral infections of vertebrate hosts which have the common feature that arthropods serve as vectors responsible for the biological or mechanical transmission of the infectious agent from host to host.

In most instances the infectious agent depends on the vector not only as a carrier but also as a definitive host and even as a reservoir. Representative viruses biologically dependent on vectors are known from each continent, and there is evidence that one or more representatives are found in most major geographical areas where an intensive search is made. Many of these viruses, formerly thought to be quite restricted in geographical distribution, are now known to be of intercontinental distribution. Several viruses will be included as suspected arthropod borne agents because of close relationship to known representative members or the circumstances of their isolation.

Hdb. d. Virusforschg. IV. (3. Erg.-Bd.) 


\section{Composition of the Group.}

At the present stage of knowledge arthropod borne viruses are generally classified into subgroups by an artificial and historical system based on the areas from which they were first isolated, the type of disease they cause in either natural or experimental hosts, the type of vector by which they are transmitted or the perpetuation dependence of the virus on its vector. While such a system is at times artificial and always presents difficulties, it will at least serve as a framework for the known representatives. The following discussions will indicate some of the difficulties of devising a more orderly arrangement. The problem of developing a binomial Linnean classification for these viruses is currently under consideration but generally is felt to be premature (HAMmoN, 1953; Lépine, 1953; Sabin, 1953).

\section{Classical Arthropod Borne Viruses.}

The classical representatives are yellow fever, dengue fever and sandfly (phlebotomus) fever. These were the first viruses recognized as being arthropod borne and they are specific examples and models of viruses that, for transmission and perpetuation, are dependent on their mosquito or sandfly vectors. In each of these infections there have been periods when knowledge of the etiology, infectious process, vector relationships and general epidemiology appeared to be well understood. However, developments in the past ten to twenty years indicate we have not reached a static status of knowledge. As examples, dengue and sandfly fevers each have at least a dual virus etiology and by definition we should really consider the respective diseases as dengues Type 1 (Hawaiian) and Type 2 (New Guinea) and sandfly fever Naples and Sicilian types (SABIN, 1955). Epidemic and jungle types of yellow fever, while caused by a single virus, have distinct epidemiological patterns. However, it is clear that this classical triad of virus infections so long accepted as established must now be reconsidered as a group of five diseases of distinct etiology (cf. Appendix p. 194).

\section{American Mosquito Borne Encephalitis Viruses.}

In the Americas at least nine distinct viruses are recognized as having association with mosquito vectors and producing an encephalitis syndrome in natural or experimental hosts (cf. Appendix p. 194/95). Communications with research workers in this region indicate they have isolated additional as yet unnamed and undesribed agents which will belong in this group. Mosquito vector relationships of the Western equine, Eastern equine and St. Louis viruses have been studied in the most detail. The other six representatives have all been isolated from naturally infected mosquito vectors, but studies of their biological dependence on the vector or natural infections in vertebrate hosts are quite limited. One must question whether these unstudied agents are capable of producing an encephalitic syndrome in hosts infected by dermal routes because their classification as encephalitic agents, except for Venezuelan equine and California viruses, is largely based on the clinical syndrome occurring in experimental hosts inoculated by the intracerebral route.

\section{African Mosquito Borne Fever and Encephalitis Viruses.}

From Africa at least eleven distinct viruses other than the classical fever viruses have been isolated from or are possibly associated with mosquito vectors (cf. Appendix p. 195). These agents are sometimes classified as encephalitic 
agents on the basis of experimental host symptoms. However, it should be emphasized that agents such as West Nile and Rift Valley fever should probably be classified in the same group as the classical fever viruses on the basis of the symptoms they produce in man. There is actually little clinical evidence that any of these agents commonly produces an encephalitis in its natural infection cycle.

Bwamba and Brazzaville viruses are included in this list in spite of the fact that they have not been associated with mosquito vectors. Epidemiologically there is reason to suspect they may be associated with such vectors.

\section{Asiatic-Australian Mosquito Borne Encephalitis Viruses.}

Representatives from this geographical area are few (cf. Appendix p. 195). However, this may reflect the comparatively limited search until recent years. Sindbis virus was found associated with mosquito vectors and avian hosts soon after a search for such agents began in India (SHAH et al., 1956). No information is available on the symptoms of natural infection with this agent.

Japanese B and Murray Valley viruses are clearly representative of mosquito borne agents which produce encephalitic syndromes in naturally infected hosts.

\section{Encephalitis and Fever Virus Agents Transmitted by Acarina.}

The group of agents transmitted by Acarina is limited in number and is not as easily divided into geographical groups (cf. Appendix 195). Geographically, Colorado tick fever is known only in North America. The Russian springsummer and louping ill encephalitic agents, which are closely related if not identical, appear to extend in a broad band from the Atlantic seaboard of Europe across to the Pacific border of northern Asia. The haemorrhagic fevers recently and forcibly have come to the attention of the western world yet seem to be extensive in their distribution and recognition from the eastern edge of Europe across to the Pacific margin of Asia.

\section{Arthropod-Borne Viruses Affecting Vertebrates Other Than Man.}

This is a very artificial grouping of agents (cf. Appendix p. 195/96), including some dependent on biological transmission by vectors and others on mechanical transmission. The range of proven and suspected arthropod vectors is diverse. Some representatives are included solely on the basis of epidemiological evidence tending to incriminate vectors. None of these agents is known to produce disease in man. It must be suspected that further, more intensive research will reveal additional arthropod-borne viruses affecting particularly wild animals and of little or no direct disease importance to man. It is even probable that some of the agents already listed as American and African mosquito borne fever and encephalitis viruses may belong in this category.

\section{Infections of Man Transmitted Incidentally by Arthropods.}

Epidemiological or laboratory experimental evidence indicates that arthropods may serve as biological or mechanical vectors of a number of viruses usually transmitted by other means. For the sake of completeness these agents more incidentally associated with arthropod vectors are also listed in the Appendix p. 196. 


\section{Inter-relationships of Viruses and Vectors.}

The types of inter-relationships of vectors and animal viruses which will allow the transmission and perpetuation of the infectious agents have been subjects of extensive study. Our principal concern with classification of the various modes of transmission is to allow the grouping of agents whose propagation and transmission are governed by the same biological requirements.

HuFF's (1931) classification system for all arthropod-borne diseases would separate the arthropod-borne viruses according to two primary modes of transmission: biological propagative and mechanical. DAY and BENNETTS (1954) in their extensive review of the specificity of relationship between arthropod vectors and plant and animal viruses imply that these two types of relationship would suffice to describe the mechanism of transmission of animal viruses. However, as indicated in MEYER's (1953) review, external and internal mechanical transmission must be differentiated. The latter mode of transmission is recognized for at least poliomyelitis and coxsackie viruses, on the basis of MELNICK and Penner's (1952) studies in flies; and possibly for lymphocytic choriomeningitis with bedbugs (Mrlzer, 1942). The internal mechanical type of vector-virus relationship would also be encompassed by DAY and BenNETTs' (1954) delayedmechanical type of transmission, which is applied to certain vector-borne plant viruses.

Mechanical transmission is generally accepted as the simplest vector-virus relationship. A consideration of some of the biological factors which control the success and extent of mechanical transmission will serve as a basis for later consideration of biological vector-virus associations.

\section{Mechanical Transmission.}

Mechanical transmission would at first thought seem to be subject to few biological influences or requirements. The simile of the "flying pin", so effectively presented by Fenner, DAY and Woodroofe (1952), if taken too literally might lead the incautious student of mechanical transmission to ignore influences such as climate, vector population density, vector host preference and other controlling biological factors. This was clearly not the intention of the authors. Even in this simplest form environment affects, for example, the feeding activity, length of life, and reproductive activity of the vector and the microenvironment of the etiological agent while associated with the vector. The cycle of transmission in the field is a dynamic biological process; the laboratory model duplicating the mode of transmission may be quite simple.

The early efforts to introduce myxomatosis virus into the wild rabbit population in Australia failed and in retrospect it became obvious that one of the most important factors leading to the failure was the climatically unfavorable environment at the time (RATCLIFFE et al., 1952). Effective transmission and geographic spread occurred only when the climate favored maximal vector feeding activity and the development of a large vector population. The further studies of MYERs, Marshall and Fenner (1954) and Myers (1954) of epizootic periods reemphasized the important effect of climate on transmission, since effective spread has been largely limited to the summer months.

Studies must still be made on the effect of temperature and humidity on the duration of virus survival on contaminated mouthparts of vectors. Reports of decreases and irregularities in transmission ability of vectors on refeeding over extended periods may be due either to cleansing of the transmittory portion 
of the mouthparts or to "death" of the virus (Fenner et al., 1952). KrlHAM and DaLmat (1955) found a marked decrease of transmission of rabbit fibroma virus even though mosquito heads still contained at least 1,000 infectious doses. This may reflect virus survival in sheltered portions of the head which did not contact the host in the act of feeding.

None of the field or laboratory studies of mechanical vector-virus relationships has been extended to determine if virus can survive on the vectors for longer periods in winter than in summer. Certainly some of the mosquito vectors of myxomatosis in Australia, Europe and the Americas survive the winter period as adults. If virus survival and transmissibility are prolonged when virus is associated with hibernating or relatively inactive vectors in the winter, the vector as well as the rabbit could serve as an overwintering reservoir of infection.

Thus there are indications that climatic factors may play nearly as important a role in viruses transmitted mechanically by vectors, particularly mosquitoes, as they do in those agents requiring extrinsic incubation. One might anticipate that myxomatosis, or other viruses, when transmitted mechanically by obligatory ectoparasites such as fleas or lice, would be less affected by climatic factors because of the host surface microclimate inhabited by the vector (LockLEY, 1954).

In the laboratory a wide range of arthropods is usually capable of transmitting viruses such as myxomatosis or avian pox (DAY and BENNETTS, 1954). However, under field conditions infection may fail to spread even in the presence of populations of capable laboratory vectors. In the field the experimental vector may never feed on the host which is a source or recipient of the infection or the vector population may never reach the threshold of density which will assure repeated feeding contact with the host. The studies of MYers et al. (1954) and MYERS (1954) clearly indicate how essential these two factors are in the transmission of myxomatosis under natural conditions.

The host preference of arthropods determines which species will serve as efficient mechanical vectors of these viruses. Early in the Australian myxomatosis studies, vector-host preference was suspected to be important (RATCLIFFE et al., 1952). Subsequent studies have confirmed a surprising degree of vector specificity largely controlled by host feeding preference. The recent study by LeE et al. (1954) of blood sources of Australian mosquitoes shows that Anopheles annulipes and Culex annulirostris have a strong preference for rabbit blood. This is complementary to the field findings of Myers (1954) and Myers et al. (1954) that the same two species of mosquitoes are primary vectors of the disease in epizootics while other species not feeding on rabbits do not contribute to the spread of infection although capable of doing so experimentally. Similarly the isolations of avian pox viruses from $C$. annulirostris, Culex fatigans and probably Culex pipiens australicus by French and ReEves (1954) are supported by the aviophilic findings for these species by LEE et al. (1954). Association of representatives of the Culex pipiens complex with avian pox viruses has usually been explained by their preference for bird blood (Kligler and Aschner, 1931; French and Reeves, 1954).

As field studies are extended a detailed knowledge of the host preferences of potential vector species will undoubtedly prove essential to an understanding of the dynamics of spread of all the mechanically transmitted viruses. For a vector to be efficient it must have repeated contact with the infected and susceptible hosts, just as much as it does in infections with biological transmission such as malaria and yellow fever.

In the case of viruses which are incidentally transmitted mechanically by vectors, such as poliomyelitis, coxsackie and trachoma, the vector's feeding 
182 W.C. ReEves: Arthropods as Vectors a. Reservoirs of Animal Pathogenic Viruses.

preference for body excretions or secretions plays a major role in determining which species of Diptera will be involved and their efficiency in transmitting to a susceptible host tissue (Melnick and Dow, 1953; Herms, 1950).

The preponderance of evidence is that the various pox and similar dermal virus agents do not multiply in the vector. Several studies on fibroma virus transmission (KILHam and Woke, 1953; KrlHam and Dalmat, 1955) and possibly one experiment with myxomatosis (FENNER et al., 1952) indicate further study might be made of possible "anterior station" multiplication of virus in the head of the vector. The studies of poliomyelitis and coxsackie viruses in flies indicate they do not multiply but are excreted for many days after ingestion (MELNICK and Penner, 1952).

The amount of infectious virus available to the vector when it feeds has proven to be important. This is particularly well shown in the studies of FenNer et al. (1952) with myxomatosis, in which vectors feeding on skin lesions where the concentration of virus is maximum can transmit and those feeding on or through tissues where the concentration is low fail to transmit. This also appears in the studies on rabbit fibroma (KILHAM and Dalmat, 1955), fowlpox (BRody, 1936) and poliomyelitis and coxsackie viruses (Melnick and Penner, 1952).

The anatomy of the mouthparts of mechanical vectors, which is closely allied to feeding methods, seems to have some relationship to vector specificity and activity. Fenner and DAY (1952) have summarized this problem and indicate that if viruses are concentrated in skin lesions a range of vectors may become involved. Mouthparts become contaminated whether they are thin stylets or broad blades, as long as feeding is on dermal areas where virus is concentrated. However, those vectors whose mouth parts become contaminated by feeding on animals with viremia are largely limited to the blood "pool feeders" with the larger feeding appendages. The pox viruses represent the dermal concentrated virus group, and equine infectious anemia (STEIN et al., 1942) is the only clear representative of the viremia group. There have been no quantitative studies of the virus carrying capacity of mouth parts of different arthropod species on the basis of size or shape of such appendages. A comparison of this type for Culicidae, Simuliidae, Heleidae, Tabanidae, Siphonoptera and Anoplura should be most interesting with a virus such as myxomatosis. The qualitative evaluation of vector ability for myxomatosis reviewed by DAY and BENNETTS (1954) might well be extented into more quantitative comparisons. KLIGLER and AschNer (1929) noted marked differences in fowlpox incubation periods following the bites of $C$. pipiens and Aedes aegypti; and this could have been due to a difference in carrying capacity of the two species.

Other biological attributes of mechanical vectors suspected of affecting transmission have been: biting cycles as they correlate with host activities, the frequency with which vectors feed, and the vector's dispersal range. Arthropods such as the Acarina which are slow feeders and have long delays between successive feedings are rarely incriminated as mechanical vectors of viruses.

Generally the viral agents dependent on mechanical vector transmission are charaicterized by having a prolonged infectious period in the vertebrate host, concentration in a site readily available to the vector, and a considerable resistance to environmental influences. The vertebrate host-virus relationship is adapted to provide a long term source (reservoir) of virus. These biological adaptations conform to the requirements for virus survival when dependent on mechanical transmission by a vector and to some degree differ from the characteristics of agents transmitted biologically by vectors. 
It has been necessary to utilize myxomatosis as the primary example for the mechanically transmitted viruses, because it is the member of this group most extensively studied in laboratory and field. Laboratory studies of vector transmission of such viruses as squirrel fibroma (KILHAM, 1955), rabbit fibroma (Philip, 1942; Kilham and Dalmat, 1955), fowlpox (Brody, 1936), swine pox (SHOPE, 1940), and equine infectious anemia (STEIN et al., 1942, 1943) still require the support of extensive field observations to determine the role of suspected vectors in the natural epidemiological cycle. It is anticipated that the vectorvirus-host relationships for most mechanically transmitted viruses would be governed by equally specific biological requirements.

This brief discussion illustrates that even with simple mechanical transmission there is considerable vector specificity for viruses in this group and a wide range of biological, morphological and environmental factors is involved in determining which arthropods will serve as vectors. The degree of transmission is controlled by definite biological requirements and is not independent of vector characteristics and environmental influences.

\section{Biological Transmission.}

The viruses biologically transmitted by arthropod vectors in their natural cycles are generally completely dependent on this mechanism for their spread from infected host to susceptible host. The circumstances of viral adaptations to and dependency on a wide range of arthropod vectors and vertebrate hosts will be discussed as general characteristics of this group and specific studies utilized as examples. Insofar as possible, analogies will be drawn between studies on different viruses studied separately and not usually compared or contrasted.

It must be emphasized that the biological factors shown to affect mechanical transmission may equally affect the biologically transmitted viruses. The principal additional factor to be considered is the adaptation of these viruses to permit entry, survival, growth and exit to and from a poikilothermic arthropod host after alternate passage through a homothermic vertebrate host. As compared with mechanical vector-virus association, the arthropod phase of the biological virus cycles has stricter limitations on the vector species involved and, being a host-parasite relationship, may offer a suitable site for extended survival of the virus outside of the vertebrate host.

MEYER (1953) summarized the relationships of which one or more must be established between an arthropod and a virus for biological transmission to be considered proven:

"(1) An extrinsic incubation period between the time the insect feeds on infected plants or animals and the time it becomes infective. (2) An obligatory relationship between the insect and the virus it transmits. (3) Multiplication or increase of the viral agent in the arthropod's body. (4) A relationship between the life stage of the arthropod and its ability to transmit the viral agent. (5) Hereditary transmission of the virus through the eggs to succeeding generations."

One or more of the above relationships is generally established by intensive laboratory study under artifical conditions. Equally important and frequently separate from these experimental criteria are the requirements for epidemiological confirmation of transmission of a viral agent by a particular arthropod in the natural infection cycle. Once again a succinct summary by MEYER (1953) illustrates the major criteria to be established. 
"(1) A close, not necessarily constant, association of an arthropod with the clinically or subclinically infected. (2) Regular visits by the insect to the healthy under conditions suitable for exchange of the virus. (3) The presence of the infective viral agents in the arthropod in nature or in the infected, but again not necessarily the sick. (4) Experimental production of the infection, or preferably the disease, by the arthropod, through feeding or visits under controlled conditions, with adequate checks."

Establishment of the necessary points from the preceding two sets of criteria for any specific viral agent or arthropod species suspected as a vector is demanding. This is illustrated by the relatively slow progress achieved in such studies and the existing lacunae in knowledge in spite of the extensive efforts by workers in this field.

\section{Natural Infections.}

A search for infected vectors collected from natural habitats has been productive with this entire group of infectious agents. Studies of this type have: led to discovery of infected arthropod species which are most highly suspected of being vectors, added to the knowledge of the geographical distribution of the viruses, served as a lead to animal hosts and reservoirs of the viral agents by their vector association, offered promise as a measuring device for determining endemic levels of infection, and resulted in the isolation of previously unknown viruses.

In intensive testing of field-collected mosquitoes to isolate such virus agents as yellow fever and the North-American encephalitides, a host of new viruses has been found associated with mosquitoes. Among these are; Semliki forest, Bunyamwera, Ntaya, Uganda S., Zika, Sindbis, California, Ilhéus, Anopheles A, Anopheles B and Wyeomyia viruses (see Table 1 for references). It remains to be proven that any of these agents are of major significance in the causation of disease in man or other vertebrates.

Finding an infected arthropod under natural conditions cannot be interpreted as evidence that the species or individual is a vector. The significance of such findings in terms of infectiousness or transmission abilities remains unknown. This doubt has frequently been ignored, and as a result numerous publications refer to arthropod species as proven vectors solely on the basis of a single or several natural associations of the arthropod with the infectious agent. In the case of viruses which are biologically dependent on the vector two questions are obviously to be answered prior to final interpretation of the significance of the isolation: What is the fate of ingested virus? To what degree does the suspected vector have contact with host sources of virus and later with susceptible hosts?

\section{Fate of Ingested Virus.}

In analyzing vector-virus interrelationships four basic types of information must be obtained before the significance of this infectious process in the arthropod can be adequately interpreted:

(1) The range of vector species which normally ingest the virus in question.

(2) The infection rates in the vector population under natural endemic or epidemic conditions.

(3) The threshold of virus concentration leading to infection of each of these species.

(4) The transmission (infectivity) rate of infected vector populations. 
The arthropod species which might normally ingest a virus are usually determined by testing extensive samples of suspect species collected in an endemic area for the virus in question. The more extensive studies of this type have been carried out with only a few of the viruses with which we are concerned: yellow fever; Western, Eastern, St. Louis, Japanese B und Russian spring-summer encephalitis; West Nile virus; blue-tongue of sheep, Rift Valley fever and possibly the hemorrhagic fever viruses. Results of such surveys will not be listed in detail, because the most significant studies are summarized elsewhere: yellow fever (Whitman, 1951); the American encephalitides (Ferguson, 1954); Japanese B encephalitis (Hammon et al., 1949); West Nile virus (TAYlor and HuRLbut, 1953); Rift Valley fever (SmIthBuRN et al., 1948); Russian spring-summer encephalitis (Silber and Soloviev, 1946); blue-tongue (Du Toit, 1944; Price and HARDY, 1954); hemorrhagic fever (GAJDUSEK, 1953); and general review of numerous agents (DAY and BENNETTS, 1954). Survey studies of this type have epidemiologically incriminated arthropod species as vectors which were previously unsuspected of having any significance in disease transmission. Examples are Haemagogus spegazzinii (capricornii) for yellow fever (Shannon et al., 1938); Culex tarsalis for Western equine and St. Louis encephalitis (HAMmon et al., 1941); Culex tritaeniorhynchus for Japanese B encephalitis (MITAMURA et al., 1938; HaMmon et al., 1949); Culiseta melanura and Mansonia perturbans for Eastern equine encephalitis (HowITT et al., 1949; ChamberlaIN et al., 1951); Mansonia tittilans for Venezuelan equine encephalitis (GILYARD, 1944); and Eretmapodites chrysogaster for Rift Valley fever (SMITHBURN et al., 1948). At the same time this general survey technique has clarified that certain previously highly suspect arthropod species rarely or never come in contact with the viral agent under study in their natural habitats or that they are refractory to the infection.

Accurate measurement of infection rates in vector populations has received remarkably little attention. Very crude indices are usually based on the number of virus isolations from an over-all sample or number of pools of vectors tested. Inevitably more accurate and interpretable techniques are going to have to be developed and applied to differentiate infection rates in biting versus non-feeding segments of the vector population, and for clearer demarcation of the significance in differences of crude infection rates between vector species.

The discovery of an arthropod species naturally associated with a viral agent is not conclusive evidence that the species is a vector; it is actually evidence only that the vector has come in contact with the infectious agent at some time in its life. The association may represent any part of a spectrum which ranges from surface contamination to a transient gut contamination to a biological infection with cellular invasion and multiplication. The extent of virus-vector relationship must usually be clarified by laboratory experimentation. Few of the viruses in this group have been studied in a sufficient variety of potential vector species prior to field surveys to allow the exclusion of any species on the premise that they were refractory to the virus. Similarly knowledge of biological attributes of the various suspected vector species is usually too limited to allow the exclusion of many species from at least preliminary study.

A sufficient number of the viruses has now been studied in a large enough variety of arthropod species in the laboratory and field that certain general characteristics controlling the probability of vector-virus association are clear. For successful virus-vector association it can be assumed that the vector must have certain physiological and morphological attributes favorable to the virus and that the vector must have biological traits, particularly with regard to its 
feeding habits, which will assure perpetuation of the basic infection chain essential to the virus. These factors are not peculiar to vector-virus relationships nor are they new. Rather they conform to the general biological laws controlling all arthropod-borne infections long accepted for other agents such as malaria and recognized very early with the classical epidemic mosquito-borne viruses of yellow and dengue fevers.

When various arthropods are experimentally exposed to one of these viruses, some species are receptive and others are refractive. Furthermore, within the acceptive species there is marked variation among strains, races and individuals in the virus concentration threshold required to produce infection. One must suspect there is a wide range or spectrum of susceptibility within a single species, much as in vertebrate infections; and similarly a range of ability to shed or transmit the virus. These variabilities in yellow fever and the encephalitides have been studied intensively and extensively.

In yellow fever a wide range of arthropods in addition to mosquitoes can be infected experimentally (Whitman, 1951). The same is true for several of the encephalitis agents (Ferguson, 1954 ; Chamberlain, Sikes et al., 1954). However, it is clear from such studies that one must guard against accepting too readily the obligatory relationship of any virus and a specific vector species solely on the basis of experimental laboratory association. In yellow fever and the encephalitides, one may get lost in a morass of experimental vector potentialities (susceptibles) many of which actually attest to the great adaptability of these viruses to different arthropod species under artificial conditions. Similarly one must be cautious in interpreting the isolation of virus from several species of arthropods in the field because an infected vertebrate host is surrounded by a galaxy of blood sucking arthropods, any species of which may imbibe infected blood. In many such species virus may even persist for some time but never be transmitted.

\section{Specificity of Vector-Virus Relationship.}

The exact nature and cause of the specificity of relationship between vector species and the viruses they transmit are poorly understood as yet. In the early phases of experimental study of vector-virus association it is usually felt that there is a high degree of generic or species specificity. However, as such studies are expanded it is usually found that species or generic specific acceptance of a viral agent is very broad under optimal experimental conditions. All of the adequately studied viruses can be transmitted by more than one species of vector and usually by several genera or even different families or orders of arthropods. Both physical and physiological attributes of vectors have been investigated in attempting to explain the experimental observations.

Many workers have felt that differences in the physical structure of the intestinal tract of different arthropod species might affect transmission. In some the structure may serve as a mechanical barrier to prevent virus from reaching susceptible cells of the vector. To eliminate such a barrier the gut of vectors has been punctured. Using this technique, MerriLl and TEN Broeck (1935) with Eastern equine virus and HuRLBUT (1951) with Japanese B virus converted refractive mosquitoes to a greater transmission status and shortened the extrinsic incubation period. McLean (1955) extended these observations by comparing the ability of Culex and Anopheles to transmit Murray Valley encephalitis virus after feeding of virus, feeding of virus with gut puncture, and parenteral inoculation of virus. These studies indicate that the capacity of the cells of the vector's gut 
to allow multiplication of the virus determines whether or not an encephalitis virus is capable of undergoing a biological cycle in a given mosquito. The intestinal tract may pose both a physiological and a physical obstacle to successful virus implantation in a refractive vector species.

So little is known of the physiology of arthropods or the "nutrient" demands of these viruses that consideration has not been given to the possibility that certain arthropod species may be deficient in substances required by the virus for maintenance and multiplication.

A more detailed knowledge of plasticity and cause of virus adaptation to tissues of diverse arthropod species will indeed be prerequisite to a final understanding of their possible position as symbionts or mutualists in these hosts. The extent of host-parasite adaptation is attested to by the complete absence of pathological reaction of infected vector species.

The classical example of application of knowledge of vector specificity to distinguish viruses is the dependence of research workers on vector susceptibility for differentiation of dengue and sandfly fevers. Until the recent adaptations of these viruses to experimental mammalian hosts (SABIN, 1955) the virological classification of newly isolated strains largely depended on comparative transmission tests with Aedes aegypti and Phlebotomus pappataci. No biological, morphological or physiological factor has been identified to explain this selectivity. The same can be said for those viruses transmitted by Acarina and to which mosquitoes are refractive. Mosquito-borne agents such as Western equine, St. Louis and Japanese B encephalitis may be transmitted experimentally by Dermacentor and Ixodes ticks (Syverton and Berry, 1941; BlattNer and Heys, 1941; Silber and Soloviev, 1946). But mosquitoes are refractive to Russian spring-summer tick-borne encephalitis (SIlber and Soloviev, 1946) and to Colorado tick fever virus (EkLUND, 1954).

There is only one definitive study (SABIN, 1952) of dual virus infections in vectors, so the possibilities of interference phenomena between viruses or exchange of characteristics between agents in these circumstances cannot be fully anticipated. SABIN's (1952) demonstration of a degree of interference between yellow fever and dengue in Aedes aegypti should lead to interesting future studies with the numerous mosquito-borne viruses. Certainly the one instance in which an agent with characteristics of both Western equine and St. Louis viruses was isolated from a pool of field-collected mites (HAMmon, 1948; HAMmon et al., 1948) illustrates the potential interest and value of such study.

Up to the present a clear-cut relationship cannot be established between the numerous viruses in this whole group and specific class, family or genus of arthropod vector on the basis of the size of the virus particles, although they fall into two principle groups: small $(15-30 \mathrm{mu})$ and large $(70-125 \mathrm{mu})$ viruses. Similarly antigenic similarities or differences offer no obvious relationship to vector specificity (SABIN, 1953), including the recent classification studies by haemagglutination techniques (CASALS and BRown, 1954).

A more detailed consideration of studies of the extrinsic incubation of viruses in arthropod vectors will illustrate the complexity of the problem and deficiencies in knowledge.

\section{Extrinsic Incubation.}

The requirement of the virus to undergo an extrinsic incubation period-the time from virus ingestion by the vector to the time when the vector is infectious by its bite-has already been pointed out to be one of the major differences between biologically and mechanically transmitted viruses. With the discovery 
of this incubation requirement for yellow fever virus, REED and his associates (1911) opened the frontier for successful subsequent study of all arthropod-borne viruses as well as for study of the vector-virus association and the influence of temperature.

The extrinsic incubation period has been studied under controlled laboratory conditions for a number of the biologically transmitted viruses. Examples of these studies and summaries are: yellow fever (Davis, 1932; Bates and RocaGarcia, 1946; Whitman, 1951); Western equine and Eastern equine (ChaMBerlatn, Corristan and Sikes, 1954; Merrill et al., 1934; Merrill and Ten Broeck, 1935); Murray Valley (McLean, 1953, 1955); West Nile (Tahori et al., 1955); Rift Valley fever (SMIthBuRN et al., 1949); Russian spring-summer (Silber and Soloviev, 1946); dengue (Siler et al., 1926). From the studies of these viruses in a variety of vectors it seems that the duration of the extrinsic incubation period can be affected by temperature, virus strain or dosage, and species of vector. During the extrinsic period virus must successfully progress from the lumen of the intestinal tract to intracellular sites, multiplication takes place, and virus must reach infectious quantities in the salivary glands.

The effect of temperature has been most adequately studied for yellow fever. Davis (1932) demonstrated the inverse relationship between temperature and incubation periods, with incubation being shortened by increased temperature. The observations of BATES and ROCA-GARCIA (1946) indicated further acceleration by short daily fluctuations of temperature. Evaluations of the influence of temperature fluctuations on the incubation of other viruses in arthropod vectors have not been as critical, but all evidence favors the conclusion that temperature affects the other viruses as it does yellow fever virus and non-viral infectious agents transmitted biologically by arthropods.

The multiplication of a sufficient range of viruses in mosquito vectors has been evaluated so that a general pattern of virus growth curves is being established. A concept develops from comparison of data such as those of CHamberLaIN, Corristan and Sikes (1954) and Chamberlatn, Sikes et al. (1954) for Eastern and Western equine viruses; of McLean $(1953,1955)$ for Murray Valley virus; of Davies and Yoshpe-Purer $(1954 / 1,2)$ for West Nile and Semliki Forest viruses; and of Whitman (1937) for yellow fever virus. A minimal infectious dose of virus is necessary to establish infection in a vector; for several days following ingestion detectable virus decreases markedly, and this period is followed by marked virus multiplication and dispersal through the body of the vector. Some difference is reported-not all of these viruses have increased to a titer equal to the infecting meal; however, this has not affected transmission ability. Transmission is possible following the return of virus to high titers and its spread to the salivary glands. Individual vectors seem to differ in susceptibility to infection, since in most studies a varying proportion of vectors fed on the infectious virus suspension either do not become infected or develop different levels of virus concentration in their bodies. In some instances, even though the vectors become infected and may be shown to contain high titers of virus, some may never become infectious by their bite. These phenomena have not been studied as extensively in arthropods as in experimental vertebrate hosts. Further studies may indicate that genetic or physiological factors influence susceptibility and transmission ability within arthropod vector species as they do in vertebrate host species.

When studies on virus-vector associations have been extended beyond the completion of the minimum extrinsic incubation period, it is usually found that the vectors remain infected and infectious for the remainder of their lives 
or until the termination of observations. Occasionally it is reported that transmission ability decreases in the terminal periods of such tests.

Determinations of the amount of virus injected into a host by the bite of single infectious mosquitoes have been limited. The data on Eastern equine virus-infected Aedes aegypti (Chamberlain, Kissling and Sikes, 1954), West Nile virus-infected Culex molestus (TAHORI et al., 1955) and yellow fever virusinfected Aedes aegypti (DAvIs, 1934) indicate that many mosquitoes inoculate minimal amounts of virus. These workers found maximum vector inoculations of 100 to 1,000 infectious doses for yellow fever and West Nile viruses in monkeys and infant mice respectively and Eastern equine from 1,000 to 100,000 mouse intracerebral $\mathrm{LD}_{50}$ 's, depending on the vertebrate host and mosquito vector employed.

For each of the Diptera-transmitted viruses studied extensively, Diptera must be considered not only vectors but also definitive hosts. In many respects the arthropod is better adapted as a reservoir (long-term source) of these viruses than are the known vertebrate hosts. The vectors have no known immunity response and may disseminate the virus agents for many days, even months. This period is in contrast to the period of a few days of viremia and the immunity response found in the vertebrate hosts. Transovarian transmission of the viruses by Diptera and their progeny does not occur or must be very uncommon (WHITman, 1951 ; GILleTt et al., 1950; Sabin et al., 1944; Reeves and Hammon, 1946; Davies and YoshPe-Purer, 1954/1). Many additional studies on transovarian passage of viruses have been made, but not reported in the literature because the results were negative or questionable.

During the extrinsic incubation period there is transovarian transmission of virus to the progeny of female ticks infected with Russian spring-summer encephalitis (SIlber and Soloviev, 1946), Colorado tick fever (Florio and MrLLER, 1948) and Nairobi sheep disease (Montgomery, 1917). In these instances, experimental studies were with suspected natural vectors. In addition, when mosquito-borne agents such as Western equine or St. Louis encephalitis viruses have been fed to experimental ticks, transovarian transmission has ensued (Syverton and Berry, 1941; Blattner and Heys, 1941). Smith et al. (1946) in their experimental studies of mites as vectors of St. Louis encephalitis virus, reported transovarian transmission, although subsequent studies of mites as vectors of the American encephalitides failed to confirm this (CHAMBERLAIN and Sikes, 1955; Sulkin et al., 1955; and Reeves et al., 1955).

As far as studies on the above tick-borne diseases have been carried, the extrinsic incubation period seems quite similar in character and environmental requirements to those described for viruses transmitted by Diptera. Ticks are in some ways better adapted than Diptera to be long-term reservoirs of infection, because of their longer life, longer periods between feedings, and the frequency of transmission of infection to their progeny. Possibly the same general conditions apply to the large group of tick-borne hemorrhagic fevers; the studies are not as complete or available (GAJDUSEK, 1953).

Several problems related to arthropod vector-virus interrelationships should be mentioned because their successful solution might answer currently unanswered questions. It has been appreciated for some time that strains of yellow fever, mosquito-borne encephalitides, West Nile or dengue viruses are most difficult or impossible to transmit with mosquitoes when they have been repeatedly passaged by mechanical means in vertebrate hosts (WhItman, 1951; HammoN and Reeves, 1943; Davies and YoshPe-Purer, 1954/1; Work et al., 1955; SABIN, 1952). Under such circumstances these viruses seem to lose their adap- 
tability and infectiousness to the vector, and this does not reflect a quantitative change in virus available to the vector. The same viruses have only occasionally been subjected to serial passage in arthropod vectors without intermittent passage in vertebrates, and because of technical difficulties the number of successive serial passages has been limited. However, a concomitant decrease in infectiousness or pathogenicity for vertebrate hosts has not been reported in those instances in which a number of such passages was accomplished (HuRLBUT, 1951 ; MerRILL and TeN BRoECK, 1934). It is possible that a better understanding of this problem will result from application of modern tissues culture techniques, especially under varied temperature conditions and with arthropod tissues. Trager's (1938) studies on the growth of Western equine virus in mosquito tissue cultures have not been confirmed or extended.

\section{Biology of Vectors.}

While emphasis has been placed on the interrelationships of vectors and viruses as an infectious process, it is equally important to consider the biological attributes of a vector which will bring it into frequent contact with virus sources and assure the perpetuation of transmission to further susceptible hosts. The section on mechanical transmission points out the importance of vector-host feeding preferences. They are equally important in the biologically transmitted viruses.

A great deal of emphasis has been placed on determining if suspected vectors feed on man or animal hosts which manifest disease symptoms. In a study of the epidemiology of these infections, this knowledge is essential; however, it is now appreciated that for comprehension of the total epidemiological pattern for most of the representatives of this group, it is of equal or greater importance to determine the frequency of vector feeding on a wide range of vertebrate species with viremia but primarily inapparent infections. As studies of yellow fever, dengue and the encephalitides have progressed, it has become apparent that knowledge of vector host preference is limited and we are handicapped by limitations of research tools. Our comprehension of the epidemiology of this entire group of infections would be markedly improved by an adequate knowledge of the host preference or range of hosts for proven or potential arthropod vectors of each virus. Such knowledge would interrelate the experimental data on good vertebrate sources of virus and effective vectors (Chamberlain, Sikes et al., 1954; Kissling et al., 1954; Work et al., 1955; Whitman, 1951); be a lead to unrecognized animal hosts (SMithbuRn et al., 1948; HAMmon and ReEves, 1948; Reeves et al., 1954) and would further clarify the probability that the natural animal host range of these viruses can be and is controlled by vector host range as specifically as it is by virus susceptibility of the hosts.

Not only is knowledge limited of the host range of most arthropods concerned, but also there is almost a void of information on factors controlling or governing the vector's search for food or host preference. The information available has been obtained by application of a few techniques: animal bait collections of feeding arthropods (BATES, 1949; WhITMAN, 1951); precipitin tests on blood from engorged arthropods (REEves and Hammon, 1944; LeE et al., 1954) quantitative chemotropism evaluation (REEves, 1953) and arthropod infection rates with parasites from known host groups (REeves et al., 1954; Herman et al., 1954).

The general problem and importance of relating vectors to virus sources can best be illustrated by examples. In yellow fever, at least several species of mos- 
quitoes from each of at least six genera are effective laboratory vectors (WHITMAN, 1951). Yet in extensive field sampling of innumerable species in Africa and Latin America, only several species of Aedes and Haemagogus are commonly found infected. A species such as Taeniorhynchus africanus, a good laboratory vector and one of the most common mosquitoes in tropical Africa, has never been found naturally infected (Whitman, 1951). The vertebrate species in which evidence of naturally occurring yellow fever infection or disease has been found are almost entirely limited to primates and a few arboreal associates (TAYLOR, 1951). This, again, is in spite of the fact that a much wider range of experimentally studied vertebrate species can be infected and will circulate virus. Until recently it seemed that in endemic yellow fever the ecological unit of transmission was more or less closed because of the strict host and ecological niche preference of certain arboreal Haemagogus and Aedes. Virus was transmitted outside this closed unit on those occasions when man intruded, as in the "Jungle Yellow Fever" of the Americas (TAYLOR, 1951); or in Africa when a primate virus carrier intruded into domestic environments where there was a semi-domestic vector such as Aedes simpsoni (GILlETT, 1951). The evidence is clear that the above types of vector-host relationships are essential to maintenance of this transmission cycle; however, as investigations have been extended, at least circumstantial evidence indicates additional vectors and hosts remain to be discovered. The excellent earlier studies of vector-host associations were limited largely to arboreal primates and associated arthropods. There was ample evidence of infection in both, and they were studied extensively. Currently evidence of yellow fever infection has been found in Africa in circumstances leading to suspicion of hitherto unsuspected and unstudied hosts and vectors such as the Galagos (bush baby) and its ectoparasites (LUMSDEN, 1955).

Western equine encephalitis will serve well for comparison with yellow fever. Again there are innumerable experimental vector species representing six genera of mosquitoes (Ferguson, 1954; Chamberlain, Sikes et al., 1954), and the occurrence of natural infection in vectors is much more limited than the experimental vector studies might lead one to expect (REEves, 1951; Ferguson, 1954). Over most of the endemic area of infection, Culex tarsalis is the primary vector species naturally associated with the virus (REEves, 1951; EkLUND, 1954). However, with Western equine virus there has been a much broader range of mosquito species occasionally found infected (secondarily) than in yellow fever, which means they at least occasionally contact hosts with viremia. The range of species, both mammalian and avian, in which evidence is often found of Western equine infection, is much broader than for yellow fever and actually covers most species found susceptible to experimental infection, many of which have not been studied (FERGUSON, 1954).

All evidence indicates that with Western equine encephalitis, in contrast to yellow fever, the ecological unit of transmission is much more open and the catholic host range and ecological adaptability of the primary vector (C.tarsalis) provide the principal explanation (REEves, 1951).

These two examples serve to emphasize the essentiality of the ecological field study for evaluation of the applicability of laboratory findings and complete understanding of the natural infection cycle between hosts and vectors. There is ample reason for thinking that the natural host distribution of this entire group of viruses is controlled by vector host feeding range as specifically as by host virus susceptibility range. It must be reemphasized that entomological investigations of vector blood sources cannot be limited to those hosts showing clinical illness because hosts with inapparent infections are frequently more 
important sources of vector infection than are those hosts with clinical illness. In addition, what appears to be a single species of mosquito may exhibit markedly different host preferences in different areas (GILLETT, 1955).

In present and future studies of the arthropod-borne virus diseases it must be accepted that these agents are not necessarily confined to the geographical distribution of a single vector species or closely related species. Generally they will be confined to those areas where any efficient vector species, effective vertebrate virus source and ecological conditions for propagation coincide and come into intimate contact with each other. This is emphasized because of the frequent reference to the fact that a specific virus cannot occur beyond the geographical limits of a single principal vector species. Historically malaria, relapsing fever and the rickettsial spotted fevers are examples of the fallacy of such reasoning. For the viral agents, yellow fever possibly spread from Africa to Latin America, and if so certainly became established most successfully by adapting to new vectors (TAYLOR, 1951). Japanese B encephalitis for a short period thrived on Guam, where no Culex tritaeniorhynchus occur (REEves and RudnICK, 1951). Western equine encephalitis occurs in areas such as Argentina, Michigan, New Jersey and Alabama, where Culex tarsalis is unknown (American Geographical Society, 1954); blue-tongue is now in the United States with species of Culicoides other than Culicoides pallidipennis as vectors (PRICE and HARDY, 1954); and the Russian spring-summer-louping ill complex is certainly not restricted to the distribution of a particular species of Ixodes or Dermacentor tick (American Geographical Society, 1954).

\section{Vector Population Measurement.}

The basic epidemiological need for measuring vector populations has been to obtain a quantitative estimate so that they can be weighed against estimates of the number and proportion of infected vectors and vertebrate hosts. The techniques employed have been based on a wide range of vector biological activities and at best must be classified as indices of population fluctuations rather than census measurements. Vector sampling has been done by collecting resting shelter populations; utilizing light, chemotropic or animal attractants; by random sweeping; or by examination of collected hosts for ectoparasites. A review of past efforts leads to the conclusion that in studies of the vectors of virus infections we have been able only to substitute the crudest indices of vector activity incidence for population measurement, and the related indices of vector infection rates have been measured in the crudest way of all. The infectivity (transmission by bite) rate of naturally infected vector populations has rarely been tested. In future developments advances in epidemiological understanding or control evaluation must be based in part on evaluating the relative importance of vector population numbers and attack rates on vertebrate hosts in comparison to vector infection and infectivity rates. Techniques will be developed for more sensitive measurement of vector infection rates to replace the current procedure of applying the number of isolations to total sample or number of pools of vectors of miscellaneous size tested. Furthermore the proportion of naturally infected mosquitoes capable of transmitting if they bite a susceptible host must be studied. Until these factors have been studied in the field, it will be difficult to apply the extensive available laboratory data on vector efficiency. With epidemic yellow fever and possibly dengue, considerable effort was made to establish a vector population index which could be applied epidemiologically (TAYLOR, 1951). Little practical application has been made of even this index, and it did 
not encompass vector infection rates. At the present time the relative importance of vector population activity or numbers versus vector infection or infectivity rates has not been accurately determined for any arthropod-borne virus. Until this is done the interdependence of these variables will be poorly understood.

Space does not permit detailed consideration of flight range and other vector movements as they relate to the spread of virus infections. With impressive frequency, otherwise unexplained spread or unexpected appearance of infection with a number of virus agents (yellow fever, encephalitis and myxomatosis) have been explained by conjecturing that vectors were possibly wafted aloft by air currents and carried great distances, where new foci of infection were established. With repetition, hypotheses of this type tend to become accepted as fact without proof or disproof. In most instances other hypotheses are equally attractive biological possibilities. One is that virus is spread by movement of infected vertebrate hosts. Another is that the infection has been endemic in latent infections of hosts and vectors, but has not become apparent before.

\section{Vectors as Reservoirs.}

The circumstances that allow most of the arthropod-borne animal viruses to persist in a specific locality over long periods remain obscure. Most of these viruses must escape from the vertebrate host to a vector in the very short period of maximum viremia or they will be eliminated by the host's immunity response. This concept undoubtedly originated in the classical studies of urban yellow fever and dengue and is especially applicable when these infections occur in temperate areas. Continual transmission from infected host to vector to susceptible host seems to be essential for these urban epidemics. In such instances there is no true virus reservoir because the longest persistence in a single host is for the life of a mosquito vector, relatively short with Aedes aegypti in the summer.

For purposes of this discussion, reservoir will be defined as "a vertebrate or invertebrate host in which virus is maintained for a prolonged period". As an example, ticks are effective reservoirs of viruses such as Russian spring-summer encephalitis (SILber and Soloviev, 1946) and probably Colorado tick fever (Florio and Mrller, 1948) and Nairobi sheep disease (Montgomery, 1917). The ticks are long-lived, virus may be transmitted to successive generations, and the ticks can remain infected and infective through the winter. In such instances the virus can be maintained in the vector for prolonged periods without resort to vertebrate passage. Within the above definition, this is a true reservoir status. In contrast vertebrate hosts are infectious for a few days and serve to disseminate virus to other ticks only during this time.

The viruses transmitted by Diptera have no obvious reservoir for perpetuation of infection except in mosquito vectors that, once infective, may remain so for life. Epidemic yellow fever, dengue and sandfly fever seem to disappear from temperate areas with the onset of winter and must be reintroduced in the summer. In tropical areas the persistence of these virus infections, and in addition jungle yellow fever, has frequently been explained by the mechanism of wandering epidemic and endemic centers in which constant spread to non-immune populations in contact with vectors maintained the infection. In this concept a long-term reservoir in a vertebrate or invertebrate host was not required. In recent years this hypothesis has been challenged with increasing frequency by the students of yellow fever. Evidence is found of circumstances in which yellow fever has persisted or reappeared at a low level of infection where a large proportion of primate hosts was immune and vectors were abundant, or through prolonged 
dry periods when adult mosquitoes were probably aestivating (TAYLOR, 1951; LUMSDEN, 1955).

This is similar to the problem encountered with the encephalitides endemic in temperate areas. Western equine, Eastern equine, St. Louis and Japanese B viruses may become active in discrete geographical regions each summer following long winter periods in which there is no possibility of active transmission (REEves, 1951; EkLund, 1953, 1954; Meyer, 1953). The questions of how these viruses overwinter and of what is their true reservoir are unanswered today. The more obvious possibilities being investigated are that overwintering adult vectors maintain the virus, occasional vertebrate hosts may have chronic infections, or migratory avian hosts from more temperate areas may reintroduce infection each summer. Supporting published data for each of these possibilities are very limited. HURLBUT (1949) found that mosquitoes could transmit Japanese B virus after experimental hibernation. The few attempts to isolate encephalitis viruses from hibernating mosquitoes collected in endemic areas have failed (HAMmon, Reeves et al., 1945; Hammon, Reeves and Galindo, 1945; Hammon and Reeves, 1947; Keener, 1952). Critical studies have not been made of the possibility that long-term chronic or relapsing infections in vertebrate hosts may be sources of vector infection. ANDERson (1954) and BURNET (1952) have presented circumstantial evidence of the relationship of migratory birds to the geographical dissemination of Murray Valley encephalitis.

It must be concluded that for all except the tick-transmitted viruses there is no proof that vectors serve as reservoirs of the viruses through periods unfavorable for active transmission. However, vectors do deserve extensive additional study in this regard. Relatively little is known of the life span of adult vectors under natural conditions or the number of times they refeed. The knowledge of relationship of temperature and humidity to vector-virus infections is still quite limited and will need to be extended through studies under a wider range of simulated climatic conditions in the laboratory as well as the field.

The possibility must still be considered that different arthropods such as mites and ticks or even helminths may serve as reservoirs of virus during unfavorable times and that mosquito vectors serve as accelerating disseminators during favorable periods. This has been suggested for the mosquito-borne encephalitides (Smith et al., 1946; Reeves, 1951) and yellow fever (Lumsden, 1955). At this time this must be considered an hypothesis. There is more than a casual possibility that discovery of the true reservoir for any one of the mosquito-borne viruses will be equally applicable to other representatives in this group.

Appendix. Animal pathogenic viruses associated with arthropod vectors.

Common Name

Sources of Additional Information or Summaries

1. Classical Fevers

Yellow fever

Dengue type 1 (Hawaiian)

Dengue type 2 (New Guinea)

Sandfly fever (Naples)

Sandfly fever (Sicilian)
Strode, 1951

Sabin, 1955

Sabin, 1955

Sabin, 1955

Sabin, 1955

2. American Mosquito-borne Encephalitides

Western equine encephalomyelitis

Eastern equine encephalomyelitis

Venezuelan equine encephalomyelitis
Ferguson, 1954

Ferguson, 1954

Gilyard, 1944; Eklund, 1954 
Common Name

St. Louis encephalitis

California

Ilhéus

Anopheles A

Anopheles B

Wyeomyia
Sources of Additional Information or Summaries

Ferguson, 1954

Hammon and Reeves, 1952; Hammon et al, 1952; Reeves and Hammon, 1952

Laemmert and Hughes, 1947

Roca-Garcia, 1944

Roca-Garcia, 1944; Hughes and Perlowagora, 1950

Roca-Garcia, 1944

3. African Mosquito-borne Fevers and Encephalitides

West Nile

Semliki Forest (Kumba)

Bunyamwera

Ntaya

Uganda $\mathrm{S}$

Rift Valley fever

Zika

Mengo

Bwamba*

Sindbis

Brazzaville (Allenopithecus) *
Dick, 1953; Taylor and Hurlbut, 1953;

Hurlbut, 1953; Work et al., 1955

Smithburn and Haddow, 1944; Dick, 1953

Smithburn et al., 1946; Dick, 1953

Smithburn and Haddow, 1951; Dick, 1953

Dick and Haddow, 1952; Dick, 1953

Smithburn et al., 1948

Dick et al., 1952; Dick, 1953

Dick, 1953

Smithburn et al., 1941; Dick, 1953

Taylor et al., 1955

Pellissier, 1953, 1954

4. Asiatic-Australian Mosquito-borne Encephalitides

Japanese B

Murray Valley

Sindbis
Sasa and Sabin, 1950; Hammon et al., 1949; Mitamura et al., 1950

Anderson, 1954; Reeves et al., 1954; McLean, 1953

Taylor et al., 1955; Shah et al., 1956

5. Acarina-borne Encephalitides and Fever Agents

Colorado tick fever

Russian spring-summer encephalitis (including louping-ill)

Hemorrhagic fevers

Crimean

Omsk

Bukovenian

Uzbekistan

Korean **
Florio and Miller, 1948; Eklund et al., 1955

Silber and Soloviev, 1946; Pond et al., 1953

Silber and Shubladze, 1945; Gordon et al., 1932

Gajdusek, 1953

Gajdusek, 1953

Gajdusek, 1953

Gajdusek, 1953

Gajdusek, 1953

Traub et al., 1954

6. Arthropod-borne Viruses Affecting Vertebrates Other Than Man

a) Mechanical transmission

Rabbit myxomatosis

Rabbit fibroma

Squirrel fibroma

Avian pox viruses

Swine pox

Equine infectious anemia

Aragão, 1943; Andrewes, 1954; Day and Bennetts, 1954

Kilham and Dalmat, 1955; Kilham and Woke, 1953

Kilham, 1955; Kilham et al., 1953

Brody, 1936; French and Reeves, 1954

Shope, 1940

Stein et al., 1942, 1943

* No proven relationship to arthropod vectors but suspected epidemiologically.

** Viral etiology and arthropod vector relationship suspected but unproven. 
196 W.C. Reeves : Arthropods as Vectors a. Reservoirs of Animal Pathogenic Viruses.

\section{Common Name}

b) Biological transmission Blue-tongue Nairobi sheep and goat disease South African horse sickness Ephemeral fever of cattle**

$$
\text { Sources of Additional Information }
$$
or Summaries

Du Toit, 1944; Price and Hardy, 1954

Montgomery, 1917; Day and Bennetts, 1954

Du Toit, 1944; Day and Bennetts, 1954

Mackerras et al., 1940

7. Virus Infections of Man Transmitted Incidentally by Arthropods

Poliomyelitis

Coxsackie

Trachoma

Lymphocytic choriomeningitis

Smallpox*
Melnick and Dow, 1953; Melnick and Penner, 1952

Melnick and Dow, 1953; Melnick and Penner, 1952

Wilson, 1930

Milzer, 1942; Coggeshall, 1939

* No proven relationship to arthropod vectors but suspected epidemiologically.

** Viral etiology and arthropod vector relationship suspected but unproven.

\section{References.}

American Geographical Society: Explored Areas of Arthropod-borne Viral Infections (Yellow Fever and Dengue Excepted) (Map) New York: American Geographical Society (1954).

Anderson, S. G.: Murray Valley Encephalitis and Australian X Disease. J. Hyg. 52, $447-468$ (1954).

ANRDewes, C. H.: Myxomatosis in Britain. Nature 174, 529-530 (1954).

AragÃo, H. DE B.: On Myxoma Virus in Wild Rabbits (Silvilagus minensis) and the Transmission by Aedes scapularis and Aedes aegypti (trans.). Mem. Inst. Osw. Cruz. 38, 93-99 (1943).

Bates, M.: The Natural History of Mosquitoes. New York: MacMillan Company, $1-379$ (1949).

Bates, M. and M. Roca-Garcia: The Development of the Virus of Yellow Fever in Haemagogus Mosquitoes. Am. J. Trop. Med. 26, 585-605 (1946).

Blattner, R. J. and F. M. Heys: Experimental Transmission of St. Louis Encephalitis to White Swiss Mice by Dermacentor variabilis. Proc. Soc. Exper. Biol. and Med. 48, 707-710 (1941).

Brody, A. L.: The Transmission of Fowl-pox. Cornell Univ. Agr. Exper. Station Memoir 195, 1-37. Ithaca: New York Agr. Exper. Station (1936).

Burnet, F. M.: Murray Valley Encephalitis. A. J. P. H. 42, 1519-1526 (1952).

Casals, J. and L. V. BRown: Hemagglutination with Arthropod-borne Viruses. J. Exper. Med. 99, 429-449 (1954).

Chamberlain, R. W., E. C. Corristan and R. K. Sikes: Studies on North American Arthropod-borne Encephalitides. V. Extrinsic Incubation of Eastern and Western Equine Encephalitis in Mosquitoes. Amer. J. Hyg. 60, 269-277 (1954).

Chamberlain, R. W., R. E. Kissling and R. K. Sikes: Studies on North American Arthropod-borne Encephalitides. VII. Estimation of Amount of Eastern Equine Encephalitis Virus Inoculated by Infected Aedes aegypti. Amer. J. Hyg. 60, $286-291$ (1954).

Chamberlain, R. W., H. Rubin, R. E. Kissling and M. E. Eidson: Recovery of Virus of Eastern Equine Encephalomyelitis from a Mosquito, Culiseta melanura (Coquillett). Proc. Soc. Exper. Biol. Med. 77, 396-397 (1951).

Chamberlain, R. W. and R. K. Sikes: Laboratory Investigations on the Role of Bird Mites in the Transmission of Eastern and Western Equine Encephalitis. Am. J. Trop. Med. and Hyg. 4, 106-118 (1955). 
Chamberlain, R. W., R. K. Sikes, D. B. Nelson and W. D. Sudia: Studies on North American Arthropod-borne Encephalitides. VI. Quantitative Determinations of Virus-vector Relationships. Amer. J. Hyg. 60, 278-285 (1954).

Coggeshall. L. T.: The Transmission of Lymphocytic Choriomeningitis by Mosquitoes. Science 89, 515-516 (1939).

Davies, A. M. and Y. YoshPe-Purer: (1) Observations on the Biology of West Nile Virus, with Special Reference to Its Behaviour in the Mosquito Aedes aegypti. Ann. Trop. Med. Parasit. 48, 46-51 (1954).

- - (2) The Transmission of Semliki Forest Virus by Aedes aegypti. J. Trop. Med. Hyg. 57, 273-275 (1954).

Davis, N. C.: The Effect of Various Temperatures in Modifying the Extrinsic Incubation Period of the Yellow Fever Virus in Aedes aegypti. Am. J. Hyg. 16, 163-176 (1932).

- Attempts to Determine Amount of Yellow Fever Virus Injected by Bite of Single Infected Stegomyia Mosquito. Am. J. Trop. Med. 14, 343-354 (1934).

Day, M. F. and M. J. Bennetss: A Review of Problems of Specificity in Arthropod Vectors of Plant and Animal Viruses. Canberra: Commonwealth Scientific and Industrial Research Organization, Division of Entomology, 172 pp. (1954).

Dick, G. W. A.: Epidemiological Notes on Some Viruses Isolated in Uganda. (Yellow Fever, Rift Valley Fever, Bwamba Fever, West Nile, Mengo, Semliki Forest, Bunyamwera, Ntaya, Uganda S and Zika Viruses). Trans. Royal Soc. Trop. Med. and Hyg. 47, 13-43 (1953).

Dick, G. W. A. and A. J. HADDow: Uganda S Virus: A Hitherto Unrecorded Virus Isolated from Mosquitoes in Uganda. I. Isolation and Pathogenicity. Trans. Royal Soc. Trop. Med. and Hyg. 46, 600-618 (1952).

Dick, G. W. A., S. F. Kitchen and A. J. HadDow: Zika Virus. I. Isolations and Serological Specificity. II. Pathogenicity and Physical Properties. Trans. Royal. Soc. Trop. Med. and Hyg. 46, 509-520 and 521-534 (1952).

Du Tort, R. M.: The Transmission of Blue-tongue and Horse-sickness by Culicoides. Onderstepoort J. Vet. Sci. and Animal Ind. 19, 7-16 (1944).

Eklund, C. M.: The Ecology of Mosquito-Borne Viruses. Ann. Rev. Microb. 7, $339-360$ (1953).

- Mosquito-transmitted Encephalitis Viruses. A Review of Their Insect Hosts and the Mechanisms for Survival and Dispersion. Exper. Parasit. 3, 285-305 (1954).

EkLund, C. M., G. M. Kohls and J. M. Brennan: Distribution of Colorado Tick Fever and Virus-carrying Ticks. J. A. M. A. 157, 335-337 (1955).

Fenner, F., M. F. DAY and G. M. Woodroofe: The Mechanism of the Transmission of Myxomatosis in the European Rabbit (Oryctolagus cuniculus) by the mosquito Aedes aegypti. Australian J. Exper. Biol. and Med. Sci. 30, 139-152 (1952).

Ferguson, F. R.: Biological Factors in the Transmission of Arthropod-Borne Virus Encephalitides. Public Health Monograph No. 23. Washington: Government Printing Office, $37 \mathrm{pp}$. (1954).

Florio, L. and M. S. Miller : Epidemiology of Colorado Tick Fever. A. J. P. H. 38, $211-213$ (1948).

French, E. L. and W. C. Reeves: A Group of Viruses Isolated from Naturally Infected Mosquitoes Collected in the Murray Valley Area of Victoria and New South Wales. J. Hyg. 52, 551-562 (1954).

GaJduseK, D. C.: Acute Infectious Hemorrhagic Fevers and Mycotoxicoses in the Union of Soviet Socialist Republics. Washington: U. S. Army Med. Serv. Grad. School, Med. Sci. Publ. May 2, (1953).

Gilletr, J. D.: The Habits of the Mosquito Aedes (Stegomyia) simpsoni Theobald in Relation to the Epidemiology of Yellow Fever in Uganda. Ann. Trop. Med. and Parasit. 45, $110-121$ (1951).

- Further Studies on the Biting Behaviour of Aedes (Stegomyia) simpsoni Theobald in Uganda. Ann. Trop. Med. and Parasit. 49, 154-157 (1955). 
198 W.C. Reeves : Arthropods as Vectors a. Reservoirs of Animal Pathogenic Viruses.

Gillett, J. D., R. W. Ross, G. W. A. Dick, A. J. Haddow and L. E. Hewitt : Experiments to Test the Possibility of Transovarial Transmission of Yellow Fever Virus in the Mosquito Aedes (Stegomyia) africanus Theobald. Ann. Trop. Med. Parasit. 44, 342-350 (1950).

Gilyard, Richard T.: Mosquito Transmission of Venezuelan Virus Equine Encephalomyelitis in Trinidad. Bull. U. S. Army Med. Dep't 75 (1944).

Gordon, W. S., A. Brownlee, D. R. Wilson and J. MacLeod: Studies in Louping Ill (An Encephalomyelitis of Sheep). Int. J. Comp. Path. 45, 106-140 (1932).

Hammon, W. McD.: The Arthropod-borne Virus Encephalitides. Amer. J. Trop. Med. 28, 515-525 (1948).

- Possible Classification of the Arthropod-borne Encephalitis Viruses. Virus and Rickettsial Classification and Nomenclature, ed. Miner, R. W. Ann. New York Acad. Sci. 56, 568-573 (1953).

Hammon, W. McD. and W. C. Reeves: Laboratory Transmission of Western Equine Encephalomyelitis Virus by Mosquitoes of the Genera Culex and Culiseta. J. Exper. Med. 78, 425-434 (1943).

- - Interepidemic Studies on Arthropod-borne Virus Encephalitides and Poliomyelitis in Kern County, California, and the Yakima Valley, Washington, 1944. Am. J. Hyg. 46, 326-335 (1947).

- Western Equine Encephalitis Control Studies in Kern County, California, 1945. II. An Evaluation of the Effectiveness of Certain Types of Mosquito Control Including Residual DDT on Virus Infection Rates in Culex Mosquitoes and in Chickens. Amer. J. Hyg. 47, 93-' 102 (1948).

- California Encephalitis Virus, a Newly Described Agent. I. Evidence of Natural Infection in Man and Other Animals. California Med. 77, 303-309 (1952).

Hammon, W. MCD., W. C. Reeves, S. R. Benner and B. Brookman: Human Encephalitis in the Yakima Valley, Washington, 1942, with 49 Virus Isolations (Western Equine and St. Louis Types) from Mosquitoes J. A. M. A. 128, 11331139 (1945).

Hammon, W. McD., W. C. Reeves, B. Brookman and E. M. Izumi: Isolation of the Viruses of Western Equine and St. Louis Encephalitis from Culex tarsalis Mosquitoes. Science 94, 328-330 (1941).

Hammon, W. McD., W. C. Reeves, R. Cunha, C. Espana and G. Sather: Isolation from Wild Bird Mites (Liponyssus sylviarum) of a Virus or Mixture of Viruses from Which St. Louis and Western Equine Encephalitis Viruses Have Been Obtained. Science 107, 92-93 (1948).

Hammon, W. MCD., W. C. Reeves and P. Galindo: Epidemiologic Studies of Encephalitis in the San Joaquin Valley of California, 1943, with the Isolation of Viruses from Mosquitoes. Am. J. Hyg. 42, 299-306 (1945).

Hammon, W. McD., W. C. Reeves, and G. Sather: California Encephalitis Virus, a Newly Described Agent. II. Isolations and Attempts to Identify and Characterize the Agent. J. Immunol. 69, 493-510 (1952).

Hammon, W. McD., W. D. Tigertt, G. Sather and H. Schenker: Isolations of Japanese B Encephalitis Virus from Naturally Infected Culex tritaeniorhynchus collected in Japan. Am. J. Hyg. 50, 51-56 (1949).

Herman, C. M., W. C. Reeves, H. E. McClure, E. M. French and W.McD. Hammon : Studies on Avian Malaria in Vectors and Hosts of Encephalitis in Kern County, California. I. Infections in Avian Hosts. Amer. J. Trop. Med. and Hyg. 3, 676-695 (1954).

Herms, W. B.: Medical Entomology with Special Reference to the Health and WellBeing of Man and Animals, fourth ed. New York: MacMillan, $643 \mathrm{pp.} \mathrm{(1950).}$

HowitT, B. F., H. R. Dodge, L. K. Bishop and R. H. GorRIE: Recovery of Virus of Eastern Equine Encephalomyelitis from Mosquitoes (Mansonia perturbans) collected in Georgia. Science 110, 141-142 (1949).

Huff, C. G.: A Proposed Classification of Disease Transmission by Arthropods. Science 74, 456-457 (1931). 
Hughes, T. P. and A. Perlowagora: The Antigenic Relationships of Certain Viruses Capable of Producing Encephalitis in Mice, as Shown by Complement Fixation Tests. J. Immun. 65, 155-161 (1950).

Hurlbut, H. S.: The Transmission of Japanese Encephalitis by Mosquitoes after Experimental Hibernation. Project NM 005007 Report No. 9. Bethesda, Maryland: Naval Medical Research Institute, August 22, 1949, 4 pp. (1949).

- The Propagation of Japanese Encephalitis Virus in the Mosquito by Parenteral Introduction and Serial Passage. Amer. J. Trop. Med. 31, 448-451 (1951).

- The Experimental Transmission of a Coxsackie-like Virus by Mosquitoes. J. Egyptian Med. Ass'n 36, 495-498 (1953).

Keener, G. G., JR.: Observations on Overwintering of Culex tarsalis Coq. (Diptera, Culicidae) in Western Nebraska. Mosquito News 12, 205-209 (1952).

Kilham, L.: Metastasizing Viral Fibromas of Gray Squirrels: Pathogenesis and Mosquito Transmission. Amer. J. Hyg. 61, 55-63 (1955).

Kilham, L. and H. T. Dalmat: Host-virus-mosquito Relations of Shope Fibromas in Cottontail Rabbits. Amer. J. Hyg. 61, 45-54 (1955).

Kilham, L., C. M. Herman and E. R. Fisher: Naturally Occurring Fibromas of Grey Squirrels Related to Shope's Rabbit Fibroma. Proc. Soc. Exper. Biol. and Med. 82, 298-301 (1953).

Kilham, L. and P. A. Woke: Laboratory Transmission of Fibromas (Shope) in Cottontail Rabbits by Means of Fleas and Mosquitoes. Proc. Soc. Exper. Biol. and Med. 83, 296-309 (1953).

Kissling, R. E., R. W. Chamberlain, R. K. Sikes and M. E. Eidson: Studies on North American Arthropod-Borne Encephalitides. III. Eastern Equine Encephalitis in Wild Birds. Amer. J. Hyg. 60, 251-265 (1954).

Kligler, I. J. and M. Aschner: Transmission of Fowl Pox by Mosquitoes: Further Observations. Br. J. Exper. Path. 10, 347-352 (1929).

- Demonstration of Presence of Fowl Pox Virus in Wild Caught Mosquitoes (Culex pipiens). Proc. Soc. Exper. Biol. and Med. 28, 463-465 (1931).

Laemmert, H. W. JR. and T. P. Hughes: The Virus of Ilhéus Encephalitis. Isolation, Serological Specificity and Transmission. J. Immunol. 55, 61-67 (1947).

LeE, D. J., K. J. Clinton and A. K. O'Gower: The Blood Sources of Some Australian Mosquitoes. Australian J. Biol. Sci. 7, 282-301 (1954).

LÉPINE, P.: On the Nomenclature and Classification of Arthropod-borne Encephalitides. Virus and Rickettsial Classification and Nomenclature, ed. Miner, R. W. Ann. New York Acad. Sci. 56, 574-579 (1953).

LOCKLEY, R. M.: The European Rabbit-flea, Spilopsyllus cuniculi, as a Vector of Myxomatosis in Britain. Vet. Rec. 66, 434-435 (1954).

Lumsden, W. H. R.: Entomological Studies Relating to Yellow Fever Epidemiology at Gede and Taveta, Kenya. Bull. Entom. Res. 46, 149-183 (1955).

MaCkerras, I. M., M. J. Mackerras and F. M. Burnet: Experimental Studies of Ephemeral Fever in Australian Cattle. Melbourne: Commonwealth Council for Scientific and Industrial Research. Bull. No. 136, 115 pp. (1940).

Melnick, J. L. and R. P. Dow: Poliomyelitis in Hidalgo County, Texas, 1948. Poliomyelitis and Coxsackie Viruses from Flies. Am. J. Hyg. 58, 288-309 (1953).

Melnick, J. L. and L. R. Penner: The Survival of Poliomyelitis and Coxsackie Viruses Following Their Ingestion by Flies. J. Exper. Med. 96, 255-271 (1952).

Merrill, M. H. and C. Ten BroecK: Multiplication of Equine Encephalomyelitis Virus in Mosquitoes. Proc. Soc. Exp. Biol. and Med. 32, 421 (1934).

- - The Transmission of Equine Encephalomyelitis Virus by Aedes aegypti. J. Exper. Med. 62, 687-695 (1935).

MeYeR, K. F.: Vectors and Reservoirs of Virus Diseases. Am. J. Trop. Med. and Hyg. 2, 757-770 (1953).

McLean, D. M.: Transmission of Murray Valley Encephalitis Virus by Mosquitoes. Australian J. Exper. Biol. Med. Sci. 31, 481-490 (1953).

- Multiplication of Viruses in Mosquitoes Following Feeding and Injection into the Body Cavity. Australian J. Exper. Biol. Med. Sci. 33, 53-66 (1955). 
Milzer, A.: Studies on the Transmission of Lymphocytic Choriomeningitis Virus by Arthropods. J. Inf. Dis. 70, 152-172 (1942).

Mitamura, T., K. Mori, M. Kitaoka and S. Tenjin: Reports to the Ninth Meeting of the Committee on Encephalitis : Experiments on the Transmission of the Virus by Various Species of Mosquitoes Artificially Infected with the Virus of Japanese Epidemic Encephalitis. Tokyo Iji Shinshi 62, 812-819 (1938).

Mitamura, T., M. Kitaoka and M. Imai: Seasonal Occurrence of Mosquito and Its Infectivity of Japanese B Encephalitis Virus in Okayama City 1942. Relationship between the Grade of Epidemic and the Infectivity of Mosquito. Japanese Med. J. 3, 149-159 (1950).

Montgomery, E.: On a Tick-borne Gastroenteritis of Sheep and Goats Occurring in British East Africa. J. Comp. Path. 30, 28-57 (1917).

Myers, K.: Studies in the Epidemiology of Infectious Myxomatosis of Rabbits. II. Field Experiments, August-November 1950, and the First Epizootic of Myxomatosis in the Riverine Plain of Southeastern Australia. J. Hyg. 52, 47-59 (1954).

Myers, K., I. D. Marshall and F. Fenner: Studies in the Epidemiology of Infectious Myxomatosis of Rabbits. III. Observations on Two Succeeding Epizootics in Australian Wild Rabbits on the Riverine Plain of Southeastern Australia 19511953. J. Hyg. 52, 338-360 (1954).

Pellissier, A.: Virus encéphalomyélitique du singe isolé à Brazzaville d'un Allenopithecus nigroviridis. Ann. Inst. Pasteur 85, 593-601 (1953).

- Isolement d'un virus encéphalomyélitique à Brazzaville. II. Etude immunologique. Ann. Inst. Pasteur 86, 53-68 (1954).

Philip, C. B.: Mechanical Transmission of Rabbit Fibroma (Shope) by Certain Haematophagous Bugs. J. Parasit. 28, 395-398 (1942).

Pond, W. L., S. B. Russ and J. WARRen: The Russian Spring-summer Encephalitis and Louping Ill Group of Viruses; Relationship of European and Asiatic Strains of Russian Spring-summer Encephalitis Viruses and Louping Ill Virus. J. Inf. Dis. 93, $294-300$ (1953).

Price, D. A. and W. T. HARDY: Isolation of the Blue-tongue Virus from Texas Sheep-Culicoides Shown to be a Vector. J. Am. Vet. Med. Ass'n 124, 255-258 (1954).

Ratcliffe, F. N., K. Myers, B. V. Fennessy, and J. H. Calaby: Myxomatosis in Australia, a Step Towards the Biological Control of the Rabbit. Nature 170, $7-11$ (1952).

Reed, W., J. Carroll, A. Agramonte and J. W. Lazear: Yellow Fever: A Compilation of Various Publications. Washington: U. S. 61st Congress, 3rd Session Senate, Document No. 822 (1911).

Reeves, W. C.: The Encephalitis Problem in the United States. A. J. P. H. 41, $678-686$ (1951).

- Quantitative Field Studies on a Carbon Dioxide Chemotropism of Mosquitoes. Am. J. Trop. Med. and Hyg. 2, 325-331 (1953).

Reeves, W. C., E. L. French, E. N. Marks and N. E. Kent: Murray Valley Encephalitis: A Survey of Suspected Mosquito Vectors. Am. J. Trop. Med. and Hyg. 3, $147-159$ (1954).

Reeves, W. C. and W. McD. Hammon: Feeding Habits of the Proven and Possible Mosquito Vectors of Western Equine and St. Louis Encephalitis in the Yakima Valley, Washington. Am. J. Trop. Med. 24, $131-134$ (1944).

- - Laboratory Transmission of Japanese B Encephalitis Virus by Seven Species (Three Genera) of North American Mosquitoes. J. Exper. Med. 83, 185-194 (1946).

- - California Encephalitis Virus, a Newly Described Agent. III. Mosquito Infection and Transmission. J. Immun. 69, $511-514$ (1952).

Reeves, W. C., W. McD. Hammon, W. H. Doetschman, H. E. McClure and G. Sather: Studies on Mites as Vectors of Western Equine and St. Louis Encephalitis Viruses in California. Am. J. Trop. Med. and Hyg. 4, 90-105 (1955). 
Reeves, W. C., R. C. Herold, L. Rosen, B. Brookman and W. McD. Hammon: Studies on Avian Malaria in Vectors and Hosts of Encephalitis in Kern County, California. II. Infections in Mosquito Vectors. Am. J. Trop. Med. and Hyg. 3, 696-703 (1954).

Reeves, W. C. and A. Rudnick: A Survey of the Mosquitoes of Guam in Two Periods in 1948 and 1949 and Its Epidemiological Implications. Am. J. Trop. Med. 31, $633-658$ (1951).

Roca-Garcia, M.: The Isolation of Three Neurotropic Viruses from Forest Mosquitoes in Eastern Colombia. J. Inf. Dis. 75, 160-169 (1944).

SAbin, A. B.: Research on Dengue Durring World War II. Am. J. Trop. Med. 1, $30-50$ (1952).

- Relationships between Arthropod-borne Viruses Based on Antigenic Analysis, Growth Requirements, and Selective Biochemical Inactivation. Virus and Rickettsial Classification and Nomenclature, ed. Miner, R. W. Ann. New York Acad. Sci. 56, 580-582 (1953).

- Recent Advances in Our Knowledge of Dengue and Sandfly Fever. Am. J. Trop. Med. and Hyg. 4, 198-207 (1955).

Sabin, A. B., C. B. Philip and J. R. PAUl: Phlebotomus (Pappataci or Sandfly) Fever. A Disease of Military Importance. Summary of Existing Knowledge and Preliminary Report of Original Investigations. J. A. M. A. 125, 603-606 and $693-699$ (1944).

SASA, M. and A. B. SABIN: Ecological Studies on the Mosquitoes of Okayama in Relation to the Epidemiology of Japanese B Encephalitis. Am. J. Hyg. 51, 21-35 (1950).

Shah, K. V., H. N. Johnson, T. R. RaO, P. K. RaJagopalan and B. S. Lamba: Isolation of Five Virus Strains of Sindbis Virus in India. Indian J. Med. Res., in press (1956).

Shannon, R. C., L. Whitman and M. Franca: Yellow Fever in Jungle Mosquitoes. Science 88, 110-111 (1938).

Shope, R. E.: Swine Pox. Archiv für die gesamte Virusforschung 1, 457-467 (1940).

Silber, L. A. and A. K. Shubladze: Louping-ill in the U.S.S.R. Am. Rev. Soviet Med. 2, 339-341 (1945).

Silber, L. A. and V. D. Soloviev: Far Eastern Tick-borne Spring-Summer (Spring) Encephalitis. Am. Rev. Soviet Med. (special supplement) pp. 5-74 (1946).

Siler, J. F., M. W. Hall and A. P. Hitchens: Dengue: Its History, Epidemiology, Mechanism of Transmission, Etiology, Clinical Manifestations, Immunity and Prevention. Philippine J. Sci. 29, 1-304 (1926).

Smith, M., R. J. Blattner and F. M. Heys: St. Louis Encephalitis Infection of Chicken Mites, Dermanyssus gallinae, by Feeding on Chickens with Viremia; Transovarian Passage of Virus into the Second Generation. J. Exper. Med. 84, $1-6$ (1946).

Smithburn, K. and A. Haddow: Semliki Forest Virus. I. Isolation and Pathogenic Properties. J. Immun. 49, 141-157 (1944).

- - Ntaya Virus. A Hitherto Unknown Agent Isolated from Mosquitoes Collected in Uganda. Proc. Soc. Exper. Biol. and Med. 77, 130-133 (1951).

Smithburn, K. C., A. J. Haddow and J. D. Gillett: Rift Valley Fever. Isolation of the Virus from Wild Mosquitoes. Br. J. Exper. Path. 29, 107-121 (1948).

Smithburn, K. C., A. J. Haddow and W. H. R. Lumsden: Rift Valley Fever: Transmission of the Virus by Mosquitoes. Br. J. Exper. Path. 30, 35-47 (1949).

Smithburn, K. C., A. J. Haddow and A. F. MahafFy : A Neurotropic Virus Isolated from Aedes Mosquitoes Caught in the Semliki Forest. Am. J. Trop. Med. 26, $189-208$ (1946).

Smithburn, K. C., A. F. Mahaffy and J. H. Paul: Bwamba Fever and Its Causative Virus. Am. J. Trop. Med. 21, 75-90 (1941).

Stein, C., J. Lotze and L. Мотт: Transmission of Equine Infectious Anemia by the Stablefly, Stomoxys calcitrans, the Horsefly, Tabanus sulcifrons (Macquart) and by Injection of Minute Amounts of Virus. Am. J. Vet. Res. 3, 183-193 (1942). 
202 W.C. Reeves : Arthropods as Vectors a. Reservoirs of Animal Pathogenic Viruses.

Stein, C., J. Lotze and L. Motт: Evidence of Transmission of Inapparent (Subclinical) Form of Equine Infectious Anemia by Mosquitoes (Psorophora columbiae) and by Injection of the Virus in Extremely High Dilution. J. Am. Vet. Med. Ass'n 102, 163-169 (1943).

Strode, G. K. (ed): Yellow Fever. New York: McGraw-Hill, 710 pp. (1951).

Sulkin, S. E., C. L. Wisseman JR., E. M. Izumi and C. Zarafontis: Attempts at Experimental Transmission of Western Equine Encephalomyelitis by Means of the Chicken Mite Dermanyssus gallinae (De Geer). Am. J. Trop. Med. and Hyg. 4, $119-135$ (1955).

Syverton, J. and G. BerRY: Hereditary Transmission of the Western Type of Equine Encephalomyelitis Virus in the Wood Tick Dermacentor andersoni Stiles. J. Exper. Med. 73, 507-530 (1941).

TAhori, A. S., V. V. Sterk and N. Goldblum: Studies on the Dynamics of Experimental Transmission of West Nile Virus by Culex molestus. Am. J. Trop. Med. and Hyg. 4, 1015-1027 (1955).

TAYLOR, R. M.: Epidemiology. Yellow Fever, ed. Strode, G. F. et al. New York: McGraw-Hill, pp. 431-538 (1951).

TAyLOR, R. M. and H. S. HuRlBut: Isolation of West Nile Virus from Culex Mosquitoes. J. Royal Egyptian Med. Ass'n 36, 199-208 (1953).

TAYlor, R. M., H. S. Hurlbut, T. H. Work, J. R. Kingston and T. E. FroTHINGHAM: Sindbis Virus: A Newly Recognized Arthropod-transmitted Virus. Am. J. Trop. Med. and Hyg. 4, 844-862 (1955).

Trager, W.: Multiplication of the Virus of Equine Encephalomyelitis in Surviving Mosquito Tissues. Am. J. Trop. Med. 18, 387-393 (1938).

Traub, R., M. Hertig, W. H. Lawrence and T. T. Harriss: Potential Vectors and Reservoirs of Hemorrhagic Fever in Korea. Am. J. Hyg. 59, 291-305 (1954).

Whitman, L.: Multiplication of the Virus of Yellow Fever in Aedes aegypti. J. Exper. Med. 66, 133-143 (1937).

- The Arthropod Vectors of Yellow Fever. Yellow Fever, ed. Strode, et al. New York: McGraw-Hill, pp. 233-298 (1951).

Wilson, R. P.: Folliculosis of the Conjunctiva in Animals. Cairo: Fourth Ann. Rep. Mem. Ophth. Lab., p. 63 (1929).

Work, T. H., H. S. HURLBUT and R. M. TAYLOR: Indigenous Wild Birds of the Nile Delta as Potential West Nile Virus Circulating Reservoirs. Am. J. Trop. Med. and Hyg. 4, 872-888 (1955). 